\title{
Risk Factors and Outcomes of Recurrent Candidemia in Children: Relapse or Re-Infection?
}

\author{
Mei-Yin Lai ${ }^{1,2}$, Jen-Fu Hsu ${ }^{1,2}$, Shih-Ming Chu 1,2 I-Hsyuan Wu 1,2, Hsuan-Rong Huang 1,2, \\ Ming-Chou Chiang ${ }^{1,2}$, Ren-Huei Fu ${ }^{1,2}$ and Ming-Horng Tsai ${ }^{2,3, *}$ \\ 1 Division of Pediatric Neonatology, Department of Pediatrics, Chang Gung Memorial Hospital, Taoyuan 333, \\ Taiwan; lmi818@msn.com (M.-Y.L.); jeff0724@gmail.com (J.-F.H.); kz6479@cgmh.org.tw (S.-M.C.); \\ a9277@cgmh.org.tw (I.-H.W.); qbonbon@gmail.com (H.-R.H.); cmc123@cgmh.org.tw (M.-C.C.); \\ rkenny@cgmh.org.tw (R.-H.F.) \\ 2 College of Medicine, Chang Gung University, Taoyuan 333, Taiwan \\ 3 Division of Neonatology and Pediatric Hematology/Oncology, Department of Pediatrics, \\ Chang Gung Memorial Hospital, Yunlin 333, Taiwan \\ * Correspondence: mingmin.tw@yahoo.com.tw; Tel.: +886-5-691-5151 (ext. 2878); Fax: 886-5-691-3222
}

Received: 14 December 2018; Accepted: 11 January 2019; Published: 16 January 2019

\begin{abstract}
In this paper, our aim was to investigate the incidence, clinical characteristics, risk factors, and outcomes of recurrent candidemia in children. We retrospectively reviewed all children with candidemia from a medical center in Taiwan between 2004 and 2015. Two episodes of candidemia $\geq 30$ days apart with clinical and microbiological resolution in the interim were defined as "late recurrence", and those that had 8-29 days apart from previous episodes were defined as "early recurrence". 45 patients (17.2\%) had 57 episodes of recurrent candidemia, and 24 had 28 episodes of late recurrent candidemia. The median time between recurrences was 1.8 months (range: $<1$ month to 13 months). Of those, 29 had relapsed candidemia and 28 were re-infected by different Candida species $(n=24)$ or by different strains $(n=4)$. Recurrent candidemia patients were more likely to require echinocandins treatment, had a longer duration of candidemia, and higher rate of treatment failure ( $p=0.001,0.014$, and 0.012 , respectively). Underlying gastrointestinal diseases (Odds ratio (OR) 3.84; 95\% Confidence interval (CI) 1.81-8.12) and neurological sequelae (OR 2.32; 95\% CI 1.15-4.69) were independently associated with the development of recurrent candidemia. $17.2 \%$ of pediatric patients with candidemia developed recurrent candidemia, and approximately half were re-infected. Underlying gastrointestinal diseases and neurological sequelae were the independent risk factors for recurrent candidemia.
\end{abstract}

Keywords: recurrent candidemia; late-onset sepsis; premature infants; antifungal resistance

\section{Introduction}

Candida species have become the fourth most common cause of nosocomial bloodstream infections since more than two decades ago [1]. Candidemia is associated with significant morbidity and contributes to important in-hospital mortality, especially among critically ill patients [2-4]. Most pediatric patients with candida bloodstream infections have severe underlying diseases, the presence of artificial devices, surgical risk factors, or are frequently exposed to high-risk medications [5-9]. There have been a number of studies that have focused on the epidemiology, antifungal susceptibility, clinical characteristics, risk factors, and outcomes of candidemia in children [5-11]. Currently, updated information of pediatric candidemia shows that emerging Candida isolates are nonsusceptible to fluconazole, a trend toward non-albicans Candida preponderance, and they still have high mortality [8,12-15]. 
Most studies on candidemia, whether from adult intensive care units (ICUs) or pediatric populations, almost always ignored the recurrent episodes of candidemia, and only retrieved the first episode of each patient for analysis [2,3,5-11]. Recurrent candidemia deserves greater concern, because most patients are still critically ill after surviving from the primary infection and may potentially have recurrent episodes [5,15-17]. These patients may have prolonged hospital stay, more severe illness, and persistent risk factors, which eventually lead to final mortality [15-17]. In the literature, recurrent candidemia in children has not been investigated. Furthermore, persistent candidemia and the occurrence of breakthrough candidemia have confused clinicians in regard to whether they were relapsed or re-infected [18-20]. In this study, we aimed to investigate recurrent episodes of candidemia in children and to document the incidence, clinical characteristics, and its impact on outcomes.

\section{Patients and Methods}

\subsection{Study Design, Setting, and Ethics Approval}

In a retrospective study, we examined the clinical microbiology database of Chang Gung Memorial Hospital (CGMH) to identify blood cultures that were positive for Candida spp. from all neonates and children $\leq 18$ years of age from January 2004 to December 2015. CGMH is a tertiary level, university-affiliated teaching hospital in northern Taiwan. All Candida isolates were retrieved and re-identified using Matrix-assisted laser desorption ionization time-of-flight mass spectrometry (MALDI-TOF, Bruker Biotype, software version 3.0, Dallas, TX, USA) and large-subunit (18S) ribosomal RNA gene D1/D2 domain sequencing. We excluded unidentified Candida spp., and only enrolled candidemia with signs or symptoms of infection and $\geq 1$ blood culture that was positive for Candida spp. This study and a waiver of informed consent for anonymous data collection were approved by the Institutional Review Board of the CGMH.

\subsection{Definition and Data Collection}

We defined an episode of candidemia defined as the first positive blood culture drawn from a peripheral vein that yields a Candida species, where the clinical symptoms and signs were compatible with Candida bloodstream infections (BSIs) $[9,21]$. Late recurrent candidemia was defined as the second episode of candidemia that occurred at least 30 days after the last positive blood culture positive for Candida [9,16,21,22]. For two different Candida species recovered within one week in the same patient, it was considered to be polyfungal candidemia. In cases of candidemia with more than two negative blood cultures, resolution of all septic symptoms and completion of antifungal treatment, the next positive blood culture yielding the same Candida species was sent to molecular diagnostics to document whether it was relapse or re-infection. Relapses were episodes caused by the same genus and species; re-infection was considered to be the second episode growing different Candida species after one week.

The clinical information was from the review of medical charts, and included demographic characteristics, predisposing risk factors within the preceding 30 days from the onset of Candida bloodstream infection (BSI) (defined as the day of first positive blood culture for Candida spp.), underlying diseases, and the presence of an intravenous catheter or any other artificial device at the time of candidemia.

\subsection{Antifungal Susceptibility Testing}

Antifungal susceptibility of all these Candida spp. isolates to eight antifungal agents was determined by a broth microdilution method, using the Sensititre YeastOne system (Trek Diagnostic Systems Ltd., East Grinstead, UK) according to the manufacturer's instructions [23,24]. Minimum inhibitory concentration (MIC) was recorded as the highest concentration of antifungal agent resulting in the development of a blue color. The criteria for susceptibility of all Candida isolates to eight antifungal agents were based on MIC breakpoints of Candida spp. recommended by the Clinical and 
Laboratory Standards Institute (CLSI) [25]. For uncommon Candida spp., other than C. guilliermondii, clinical breakpoints are undefined; therefore, isolates that showed MICs higher than the epidemiologic cutoff value were considered potentially resistant [26].

\subsection{Statistical Analysis}

We compared the clinical characteristics, treatment, and outcomes of the first episode of candidemia with those of the recurrent episode of candidemia. The demographic, clinical, outcome variable, and in vitro susceptibility data were summarized using the descriptive statistics. All statistical analyses were performed using IBM SPSS software (version 22.0; IBM SPSS Inc., New York, NY, USA). Categorical variables were compared using the $\chi 2$ or Fisher's exact test, and continuous variables by the Mann-Whitney U test. A $p$-value of 0.05 was considered significant.

\section{Results}

\subsection{Recurrent and Late Recurrent Candidemia}

Between January 2003 and December 2015, 262 patients less than 18 years old developed a total of 319 episodes of candidemia at CGMH (C. albicans $46.4 \%$, C. parapsilosis $27.0 \%$, C. tropicalis $5.6 \%$, C. glabrata 5.0\%, and other species 16.0\%). In this cohort, 45 patients had a total of 57 episodes of recurrent candidemia. Of these, 28 episodes in 24 patients fulfilled the criteria of late recurrent candidemia. Seven patients had more than one recurrence, and four had a total of four episodes of candidemia. All recurrent episodes that had the same Candida species as the previous one were sent to molecular typing methods. We confirmed that 24 episodes were re-infected by different Candida spp., 29 episodes were relapsed by the same Candida strains and four episodes were re-infected by different strains of the same Candida spp. (Table 1). Of all pediatric patients with candidemia, 17.2\% (45/262) had recurrent candidemia, and 9.2\% (24/262) had late recurrent candidemia.

\subsection{Characteristics of Recurrent Candidemia According to Time to Recurrence and Comparisons with First Episodes of Candidemia}

Clinical characteristics of patients with recurrent candidemia and late recurrent candidemia are summarized in Table 2. Median time to early recurrence and late recurrence was 14 days (range, 10-29 days) and 72 days (range, 32-388 days), respectively. Cases of late recurrent candidemia and early recurrent candidemia were compared first, and then both were compared with the first episodes of candidemia. We found that the characteristics of late recurrent candidemia and early recurrent candidemia were mostly comparable (Table S1). Patients with late recurrences were significantly younger (median, 1.8 years old) than patients with a single infection (median, 4.5 years; $p=0.013$ ). When compared with the first episodes of candidemia, patients with recurrences had significantly more artificial devices (other than central venous catheter (CVC)), more previous azoles exposure, and previous bacteremia (all had $p$ values $<0.001$ ). A large proportion of patients with recurrent candidemia had underlying gastrointestinal diseases (50.9\%), neurological sequelae (50.9\%), and other chronic comorbidities (Table 2). However, severity of illness and most underlying comorbidities were comparable in the first episodes and recurrent episodes of candidemia.

Most recurrent episodes were caused by non-albicans Candida species (70.2\%); C. parapsilosis, especially was more likely to be the pathogen of recurrent candidemia than C. albicans (OR, 1.48; 95\% CI 1.12-3.44, $p=0.020)$. Furthermore, 35.1\% (19/57) of recurrent candidemia were breakthrough candidemia, and most of them were early re-infected by different Candida species during antifungal treatment.

\subsection{Treatment and Outcomes of Recurrent Candidemia}

Except for nine episodes of candidemia (all were first episodes), all other candidemia were treated with antifungal agents at a median of 2 days (range, 0-8 days) after onset of candidemia. 
Approximately two-thirds of first and recurrent episodes of candidemia were treated with fluconazole (65.3\% vs. $68.4 \%$, respectively), but the rate of antifungal regimens modification in recurrent episodes of candidemia was significantly higher than that in the first episodes. Besides, the recurrent episodes were more often treated with echinocandins than the first episodes ( $45.6 \%$ vs. $23.3 \%, p=0.001)$ (Table 3 ). After modification of antifungal regimens, the recurrent episodes led to a significantly longer duration of candidemia (median 3.0 vs. 1.0 days, $p=0.014$ ), slower antifungal agent responses, and significantly higher rates of clinical treatment failure (59.6\% vs. $40.8 \%, p=0.012)$. When we excluded cases that did not receive antifungal therapy (nine episodes in total), recurrent episodes of candidemia had a relatively higher candidemia-attributable mortality rate than the first episodes of candidemia $(31.6 \%$ vs. $19.0 \%, p=0.078)$.

\subsection{Risk Factors of Recurrent Candidemia}

Because of the similar characteristics of early recurrent candidemia and late recurrent candidemia, we enrolled all cases of recurrent candidemia and compared them with those with a single episode of candidemia. In non-neonatal children with candidemia, patients with recurrent candidemia were significantly younger than those with a single episode of candidemia (median age, 4.6 years vs. 2.5 years, $p=0.022$ ). In univariate analysis, the characteristics of patients with recurrent candidemia were significantly more common, including underlying gastrointestinal diseases and neurological sequelae, presence of artificial devices other than CVC, and candidemia caused by C. parapsilosis. Disseminated candidiasis was highly associated with persistent candidemia, but was not associated with an increased risk of recurrent candidemia. Antifungal resistance of the first episode of candidemia was not significantly predisposed to the second episode, but delayed removal of CVC at the first episode was significantly associated with an increased risk of recurrent candidemia (odds ratio (OR) 2.33 ; 95\% confidence interval (CI) $1.22-4.34 ; p=0.022$ ).

A logistic regression model was constructed to evaluate independent predictors for recurrent candidemia (Table 4). After adjusting for age and sex, underlying gastrointestinal diseases (OR 3.84; 95\% CI 1.81-8.12; $p=0.001$ ) and neurological sequelae (OR 2.32; 95\% CI 1.15-4.69; $p=0.019$ ) were significantly and independently associated with the development of recurrent candidemia. The Hosmer-Lemeshow goodness-of-fit test results indicated that the recurrent candidemia model reflected the data well $(p=0.88)$. 
Table 1. Patients with recurrent candidemia: pathogens, characteristics, treatment, and outcomes.

\begin{tabular}{|c|c|c|c|c|c|c|}
\hline $\begin{array}{l}\text { Early and Late } \\
\text { Recurrences }\end{array}$ & $\begin{array}{l}\text { Candida Species of } \\
\text { Initial Episodes }\end{array}$ & $\begin{array}{c}\text { Days until } \\
\text { Recurrence (Range) }\end{array}$ & $\begin{array}{c}\text { Candida Species of Recurrent } \\
\text { Episodes }\end{array}$ & $\begin{array}{l}\text { MIC }(\mu \mathrm{g} / \mathrm{mL}) \\
\text { to Fluconazole } \\
\text { (Case Number) }\end{array}$ & Therapeutic Regimens & $\begin{array}{l}\text { Candidemia- } \\
\text { Attributable } \\
\text { Mortality, } n(\%)\end{array}$ \\
\hline \multicolumn{7}{|l|}{ Early recurrence * } \\
\hline \multirow[t]{3}{*}{ Relapsed $(n=16)$} & C. albicans (7) & $12-25$ & C. albicans (7) & $0.5(5), 16.0(2)$ & Amphotericin b (4), & $4(25.0)$ \\
\hline & C. parapsilosis (6) & $12-22$ & C. parapsilosis (6) & $0.25-2.0$ & Fluconazole (3), & \\
\hline & C. glabrata (3) & $12-20$ & C. glabrata (3) & $16(1), 32(2)$ & $\begin{array}{c}\text { Echinocandin }(8), \\
\text { Flu + Echinocandins (1) }\end{array}$ & \\
\hline \multirow[t]{5}{*}{ Re-infection $(n=13)$} & C. albicans (8) & $10-20$ & $\begin{array}{c}\text { C. parapsilosis (6), C. metapsilosis (1), } \\
\text { C. tropicalis (1) }\end{array}$ & $\begin{array}{c}0.5-1.0(5), 8(1) \\
2.0 \\
4.0\end{array}$ & $\begin{array}{c}\text { Echinocandins (5), Fluconazole (2), } \\
\text { Flu + Echinocandins (1) }\end{array}$ & $6(46.2)$ \\
\hline & C. parapsilosis (1) & 17 & C. glabrata (1) & 16.0 & Amphotericin b (1) & \\
\hline & C. tropicalis (2) & $10-15$ & C. lusitaniae (1), C. parapsilosis (1) & $0.25,2.0$ & Echinocandins (1), Amphotericin b (1) & \\
\hline & C. metapsilosis (1) & 12 & C. lipolytica (1) & 2.0 & Echinocandins (1) & \\
\hline & C. lusitaniae (1) & 11 & C. haemulonii (1) & 16.0 & Echinocandins (1) & \\
\hline \multirow{6}{*}{$\begin{array}{l}\text { Late recurrence * } \\
\text { Relapsed }(n=13)\end{array}$} & & & & & & \\
\hline & C. albicans (5) & 49-101 & C. albicans (5) & $0.25(1), 0.5(3), 16(1)$ & Echinocandins (2), Fluconazole (3) & $4(30.8)$ \\
\hline & C. parapsilosis (5) & $32-162$ & C. parapsilosis (5) & $0.5-2.0$ & $\begin{array}{l}\text { Amphotericin b (1), Echinocandins (3), } \\
\text { Fluconazole (1) }\end{array}$ & \\
\hline & C. tropicalis (1) & 31 & C. tropicalis (1) & 2.0 & Echinocandins (1) & \\
\hline & C. glabrata (1) & 34 & C. glabrata (1) & 16.0 & Amphotericin b (1) & \\
\hline & C. orthopsilosis (1) & 59 & C. orthopsilosis (1) & 2.0 & Echinocandins (1) & \\
\hline \multirow[t]{7}{*}{ Re-infection $(n=15)$} & C. albicans $(7)$ & $45-155$ & $\begin{array}{c}\text { C. albicans (2), } \\
\text { C. parapsilosis (3), } \\
\text { C. guilliermondii (1), C. tropicalis (1) }\end{array}$ & $\begin{array}{l}0.5 \\
0.5-1.0 \\
4.0 \\
2.0\end{array}$ & $\begin{array}{c}\text { Fluconazole (2), Amphobericin b (2), } \\
\text { Echinocandins (3) }\end{array}$ & $4(26.7)$ \\
\hline & & & C. parapsilosis (1), & 0.25 & & \\
\hline & C. parapsilosis (3) & $54-136$ & C. glabrata (1), & 8.0 & Fluconazole (2), Amphotericin b (1) & \\
\hline & & & C. metapsilosis (1). & 2.0 & & \\
\hline & C. glabrata (2) & $31-72$ & C. glabrata (1), C. parapsilosis (1) & $8.0,0.5$ & Fluconazole (1), Amphotericin b (1) & \\
\hline & C. tropicalis (2) & $65-114$ & C. albicans (2) & $0.5,2.0$ & Amphotericin b (2) & \\
\hline & C. metapsilosis (1) & 388 & C. albicans (1) & 0.5 & Fluconazole (1) & \\
\hline
\end{tabular}

* Early recurrence indicated the recurrence occurred within 8-29 days after the last positive blood culture of first episode of candidemia, whereas late recurrence indicated recurrence occurred at least 30 days later. 
Table 2. Comparisons of first episodes and recurrent episodes of candidemia in children.

\begin{tabular}{|c|c|c|c|c|c|}
\hline \multirow[b]{2}{*}{ Characteristics } & \multirow{2}{*}{$\begin{array}{l}\text { First Episodes of } \\
\text { Candidemia } \\
(n=262)\end{array}$} & \multicolumn{4}{|c|}{ Recurrent Episodes of Candidemia (Total $n=57$ ) } \\
\hline & & $\begin{array}{l}\text { All Recurrence } \\
\quad(n=57)\end{array}$ & $p$ Value * & $\begin{array}{l}\text { Late Recurrence } \\
\quad(n=28)\end{array}$ & $p$ Value $* *$ \\
\hline \multicolumn{6}{|l|}{ Age } \\
\hline Non-neonatal patients (years), median (IQR) & $4.5(1.4-2.1)$ & $2.9(0.9-7.2)$ & 0.059 & $1.8(0.8-7.1)$ & 0.013 \\
\hline Neonatal patients (days), median (IQR) & $22.5(14.8-44.3)$ & $57.5(39.5-79.5)$ & $<0.001$ & $66.5(52.5-76.3)$ & $<0.001$ \\
\hline Sex (male gender) & $138(52.7)$ & $27(47.4)$ & 0.559 & $13(46.4)$ & 0.556 \\
\hline Hospital days untill diagnosis, median (IQR) & $26.0(13.0-45.0)$ & $43.0(28.0-76.5)$ & $<0.001$ & $44.0(19.5-84.5)$ & $<0.001$ \\
\hline Ward & & & 0.056 & & 0.059 \\
\hline Neonatal intensive care unit & $94(35.9)$ & $12(21.1)$ & & $5(17.9)$ & \\
\hline Pediatric intensive care unit & $95(36.3)$ & $29(50.9)$ & & $12(42.9)$ & \\
\hline Burn or surgical intensive care unit & $8(3.1)$ & $5(8.8)$ & & $3(10.7)$ & \\
\hline General wards & $65(24.8)$ & $11(19.3)$ & & $8(28.6)$ & \\
\hline \multicolumn{6}{|l|}{ Underlying chronic comorbidities \# } \\
\hline Congenital or genetic anomalies & $28(9.9)$ & $11(19.3)$ & 0.078 & $5(17.9)$ & 0.256 \\
\hline Neurological sequelae & $89(34.0)$ & $29(50.9)$ & 0.023 & $17(60.7)$ & 0.005 \\
\hline Cardiovascular disease & $22(8.4)$ & $9(15.8)$ & 0.077 & $3(10.7)$ & 0.720 \\
\hline $\begin{array}{l}\text { Chronic lung disease and/or pulmonary } \\
\text { hypertension }\end{array}$ & $82(31.3)$ & 19 (33.3) & 0.756 & $6(21.4)$ & 0.387 \\
\hline Gastrointestinal sequelae & $71(27.1)$ & $29(50.9)$ & 0.001 & $17(60.7)$ & 0.001 \\
\hline Renal insufficiency with/without dialysis & $37(14.1)$ & $8(14.0)$ & 1.000 & $4(14.3)$ & 1.000 \\
\hline Hematological/Oncology cancer & $42(16.0)$ & $4(7.0)$ & 0.079 & $0(0)$ & 0.020 \\
\hline Immunodeficiency & $6(2.3)$ & $1(1.8)$ & 0.802 & $0(0)$ & 0.541 \\
\hline Autoimmune disease & $7(2.7)$ & $1(1.8)$ & 0.688 & $0(0)$ & 0.487 \\
\hline Hepatic failure or cholestasis & $12(4.6)$ & $1(1.8)$ & 0.328 & $1(3.6)$ & 1.000 \\
\hline Pathogens & & & 0.012 & & 0.806 \\
\hline Candida albicans & $131(50.0)$ & $17(29.8)$ & 0.008 & $10(35.7)$ & \\
\hline Candida parapsilosis & $63(24.0)$ & $23(40.4)$ & 0.020 & $10(35.7)$ & \\
\hline Candida tropicalis & $17(6.5)$ & $3(5.3)$ & & $2(7.1)$ & \\
\hline Candida glabrata & $12(4.6)$ & $7(12.3)$ & & $3(10.7)$ & \\
\hline Candida guilliermondii & $11(4.2)$ & $1(1.8)$ & & $1(3.6)$ & \\
\hline Other Candida spp. & $28(10.7)$ & $6(10.5)$ & & $2(7.1)$ & \\
\hline
\end{tabular}


Table 2. Cont.

\begin{tabular}{|c|c|c|c|c|c|}
\hline \multirow[b]{2}{*}{ Characteristics } & \multirow{2}{*}{$\begin{array}{l}\text { First Episodes of } \\
\text { Candidemia } \\
(n=262)\end{array}$} & \multicolumn{4}{|c|}{ Recurrent Episodes of Candidemia (Total $n=57$ ) } \\
\hline & & $\begin{array}{l}\text { All Recurrence } \\
\quad(n=57)\end{array}$ & $p$ Value * & $\begin{array}{l}\text { Late Recurrence } \\
\qquad(n=28)\end{array}$ & $p$ Value ** \\
\hline \multicolumn{6}{|l|}{ Clinical presentation } \\
\hline Severe sepsis & $102(38.9)$ & $25(43.9)$ & 0.551 & $10(35.7)$ & 0.840 \\
\hline Septic shock & $69(26.3)$ & $20(35.1)$ & 0.194 & $8(28.6)$ & 0.823 \\
\hline Progressive and deteriorated $\mathbb{I}$ & $47(17.9)$ & $14(24.6)$ & 0.266 & $4(14.3)$ & 0.797 \\
\hline Disseminated candidiasis $\$$ & $12(4.6)$ & $2(3.5)$ & 0.720 & $1(3.6)$ & 1.000 \\
\hline Breakthrough candidemia & $20(7.6)$ & $20(35.1)$ & $<0.001$ & $5(17.9)$ & 0.067 \\
\hline \multicolumn{6}{|l|}{ Predisposing risk factors \# } \\
\hline Receipt of systemic antibiotics \& & $262(100)$ & $56(98.2)$ & 0.142 & $27(96.4)$ & 0.705 \\
\hline Previous azole exposure \& & $10(3.8)$ & $24(42.1)$ & $<0.001$ & $9(32.1)$ & $<0.001$ \\
\hline Prior bacteremia & $114(43.5)$ & $46(80.7)$ & $<0.001$ & $21(75.0)$ & 0.002 \\
\hline Presence of CVC & $253(96.6)$ & $57(100)$ & 0.371 & $28(100)$ & 0.319 \\
\hline Stay in an intensive care unit & $197(75.2)$ & $46(80.7)$ & 0.565 & $16(57.1)$ & 0.080 \\
\hline Receipt of parenteral nutrition & $175(66.8)$ & $42(73.7)$ & 0.350 & $21(75.0)$ & 0.378 \\
\hline Receipt of immunosuppressants & $55(21.0)$ & $10(17.5)$ & 0.717 & $2(7.1)$ & 0.085 \\
\hline Artificial device other than CVC & $119(45.4)$ & $41(71.9)$ & $<0.001$ & $21(75.0)$ & 0.003 \\
\hline Prior surgery \& & $80(30.5)$ & $19(33.3)$ & 0.753 & $7(25.0)$ & 0.528 \\
\hline Neutropenia (ANC $<0.5 \times 10^{3} / \mu \mathrm{L}$ ) & $63(24.0)$ & $17(29.8)$ & 0.400 & $6(21.4)$ & 1.000 \\
\hline
\end{tabular}


Table 3. Antifungal regimens and outcomes of recurrent episodes of candidemia versus first episodes of candidemia.

\begin{tabular}{|c|c|c|c|}
\hline & Recurrent Episodes of Candidemia (total $n=57$ ) & First Episodes of Candidemia (Total $n=262$ ) & $p$ Value \\
\hline Duration of candidemia (days), median (interquartile range) & $3.0(1.0-9.0)$ & $3.0(1.0-6.0)$ & 0.638 \\
\hline$\leq 2$ days & $26(45.6)$ & 115 (43.9) & \\
\hline 3-7 days & $14(24.5)$ & 101 (38.5) & \\
\hline$\geq 8$ days & $17(29.8)$ & 46 (17.6) & \\
\hline Antifungal regimens for treatment & & & 0.007 \\
\hline Fluconazole/Voriconazole & $15(26.3)$ & $107(40.8)$ & 0.050 \\
\hline Amphotericin B & $14(24.6)$ & $80(30.5)$ & \\
\hline Echinocandins & $26(45.6)$ & $61(23.3)$ & 0.001 \\
\hline Combination antifungal treatment & $2(3.5)$ & $5(1.9)$ & \\
\hline None & $0(0)$ & $9(3.4)$ & \\
\hline $\begin{array}{l}\text { Effective antifungal agents given within } 48 \text { hours after onset of } \\
\text { candidemia (based on antifungal susceptibility testing) }\end{array}$ & $28 / 57(49.1)$ & $162 / 262(61.8)$ & 0.102 \\
\hline Total treatment duration (days), mean (interquartile range) & $21.0(14.0-25.0)$ & $16.0(14.0-22.0)$ & 0.338 \\
\hline Catheter removal & $33 / 57(57.9)$ & $176 / 262(67.2)$ & 0.108 \\
\hline $\begin{array}{c}\text { Removal of central venous catheter within } 3 \text { days of onset } \\
\text { Treatment outcomes }\end{array}$ & $16 / 57(28.1)$ & $105 / 262(40.1)$ & 0.082 \\
\hline $\begin{array}{c}\text { Treatment outcomes } \\
\text { Responsiveness after initiation of antifungal treatment * }\end{array}$ & & & 0.014 \\
\hline Within $72 \mathrm{~h}$ & $13(22.8)$ & 109 (41.6) & \\
\hline 4-7 days & $9(15.8)$ & $51(19.5)$ & \\
\hline More than 7 days & $16(28.1)$ & $42(16.0)$ & \\
\hline Treatment failure & $34(59.6)$ & $107(40.8)$ & 0.012 \\
\hline Modification of antifungal treatment & $32 / 57(56.1)$ & $104 / 253(41.1)$ & 0.054 \\
\hline $\begin{array}{l}\text { Duration of candidemia after effective antifungal agents (days), } \\
\text { median (IQR) }\end{array}$ & $3.0(1.0-7.5)$ & $1.0(1.0-4.0)$ & 0.014 \\
\hline Candidemia attributable mortality & $18(31.6)$ & $57(21.8)$ & 0.123 \\
\hline Early mortality ( $\leq 7$ days) & $8(14.0)$ & $27(10.3)$ & 0.482 \\
\hline Late mortality (8-30 days) & $10(17.5)$ & $30(11.5)$ & 0.267 \\
\hline
\end{tabular}

All data have been expressed as a number (percentage \%), unless indicated otherwise. ${ }^{*}$ Responsiveness to antifungal agents was defined according to the consensus criteria of the Mycoses Study Group and European Organization for Research and Treatment of Cancer [27].

Table 4. Multivariate analysis to identify the independent risk factors of recurrent candidemia.

\begin{tabular}{cccc}
\hline Variables & Odds Ratio & 95\% Confidence Interval & $\boldsymbol{P}$ \\
\hline Male sex & 1.05 & $0.54-2.05$ & 0.889 \\
Age (neonates vs. children) & 1.58 & $0.68-3.65$ & 0.286 \\
Candida parapsilosis & 2.57 & $0.89-7.42$ & 0.080 \\
Gastrointestinal underlying diseases & 3.84 & $1.81-8.12$ & 0.001 \\
Underlying neurological sequelae & 2.32 & $1.15-4.69$ & 0.019 \\
Underlying cardiovascular diseases & 2.24 & $0.85-6.69$ & 0.090 \\
Presence of artificial devices other than central venous catheter & 1.73 & $0.84-3.54$ & 0.136 \\
Catheter management of first episode of candidemia & 1.12 & $0.68-1.13$ & 0.302 \\
(delayed removal vs. early removal) & & & \\
\hline
\end{tabular}




\section{Discussion}

We found that $17.2 \%$ of pediatric patients who survived the first episode of candidemia had recurrent candidemia, and 9.2\% had late recurrence. This result was significantly higher than previous studies that were conducted in an adult population, in which $1.5 \%$ to $4.4 \%$ of recurrent candidemia was reported $[16,17,28]$. We documented that more than half of all the recurrent episodes of candidemia were re-infections, where there was a higher probability of recurrence among patients with candidemia due to C. parapsilosis. Most of the characteristics and severity of illness were comparable between the first episodes and recurrent episodes. Although not statistically significant, the candidemia-attributable mortality rate in children with recurrent candidemia was higher than that in those with a single episode of candidemia.

Before investigating the issue of recurrent candidemia, it is important to differentiate cases of persistent candidemia. Most studies only focused on late recurrence, which was defined as an episode of candidemia that occurred at least one month after the last positive blood culture of previous fungemia $[16,17,28-30]$. In a recent study, only two episodes of candidemia $\geq 30$ days apart with clinical, and microbiological resolution in the interim were enrolled [16]. In another study, a second episode caused by different Candida species (no mention of time interval) was considered as late recurrence [17]. However, we found that $22.8 \%$ (13/57) of recurrence were re-infection caused by different Candida species at 8-30 days after the previous episode, which was ignored in previous studies $[16,17,28-30]$. Although previous studies excluded cases of persistent candidemia, they may understate some episodes of early recurrent candidemia. Furthermore, we found that early re-infection candidemia had the highest candidemia-attributable mortality of $46.2 \%$. Although our data was limited by the number of cases, as we are the first to consider early recurrent candidemia, the clinical significance remains a matter of debate.

In this study, we found that most characteristics of late recurrent candidemia and early recurrent candidemia were similar (Supplementary Table S1). We also found that re-infection and relapsed episodes were also comparable with regard to their characteristics. Therefore, our results can be compared with other studies of recurrent candidemia, which only enrolled episodes of late candidemia.

This study included all neonates and children with admissions in different wards or units, and some of their characteristics may be completely different. For example, immunodeficiency and autoimmune diseases were noted only in children. The treatment policies of data antifungals in children and neonates were also different. Therefore, all of their predisposing factors were considered in the analyses to identify independent risk factors for recurrence. Besides, the timeframe of the study period was long, and the antifungal options and guideline were changed during the study period (e.g. echinocandins were more widely used since 2007 in our institute). However, we previously documented that the treatment outcomes did not change over the study period [31]. Furthermore, although more non-albican Candida species, as well as antifungal resistant Candida isolates were noted in the recurrent episodes, initial antifungal agents did not independently affect the final outcomes [31].

The enrolment of early recurrent candidemia may explain the significantly higher rate of candidemia recurrence in our cohort. Furthermore, most pediatric patients survived their first episode of candidemia, and they were still at risk of subsequent candidemia, including numerous chronic comorbidities, immunocompromised status, and the presence of an intravenous catheter or other artificial devices. Therefore, the incidence of recurrent candidemia in children was significantly higher than that in adults $[16,17]$. We also found that most mortality in children with candidemia resulted from recurrent infection, subsequent infectious complications, and organ damage, which is consistent with our previous study [32].

Recent studies have found more recurrent candidemia to be re-infections [16,17], contrary to earlier studies that suggested that most recurrent episodes represent persistent, rather than recurrent infections [28-30]. In this study, re-infection accounted for $49.1 \%(28 / 57)$ of recurrence. The trend of more re-infections and less persistent (or relapsed) candidemia may be due to different treatment strategies, increasing non-albicans candidemia, and increasing Candida species that have antifungal 
resistance $[22,33]$. This is compatible with our result that non-albicans candidemia accounted for the majority of recurrent candidemia. We found most of our patients still had chronic comorbidities and risk factors after they survived the first episode of candidemia. These recurrences should be caused by the persistence of particular risk factors for candidemia rather than inadequately treated infections. Thus, this is the scenario where the pediatric patient with candidemia was first treated successfully, but the persistence of chronic underlying diseases makes him susceptible to another episode of candidemia caused by non-albicans Candida species after antifungal selection.

Among the risk factors for candidemia, underlying gastrointestinal sequelae were independently associated with recurrent candidemia after multivariate logistic regression, which is consistent with previous studies [16,17]. Both Muñoz et al. [16] and Asmundsdottir et al. [17] found that more than half of the patients with recurrent candidemia had an underlying gastrointestinal disease. In our cohort, gastrointestinal sequelae were the most common underlying chronic comorbidities in patients with recurrent candidemia (50.9\%). Because Candida species commonly colonize in the human gastrointestinal tract as a component of the resident microbiota [27,34], it is possible that these microorganisms may serve as the sources of invasive infection during immunocompromised status and/or impaired gastrointestinal function.

Our result is consistent with previous studies that $C$. parapsilosis accounts for a significant proportion of recurrent candidemia [16,30]. In this study, we also found that all episodes of recurrent candidemia occurred in patients with CVC in place, and there was a significantly higher proportion of other artificial devices $(71.9 \%)$ in these patients. Because C. parapsilosis is well-known for its ability to form biofilm on implanted devices [35,36], we suggested that the presence of artificial devices clotted with biofilm-candida complex may serve as another important source of recurrence. Further studies regarding the microbiological characteristics of biofilm-forming Candida isolates and new strategies to eradicate the residual microorganisms after initial candidemia may contribute to decreasing the incidence of recurrent candidemia.

In our institute, empirical antifungal agent is prescribed only when clinical candidiasis is suspected, and this depends on the physician's decision. We did not have a specific policy of antifungal prophylaxis in the neonatal or pediatric intensive care unit. Because it is often difficult to distinguish candidemia from bacteremia in the beginning, clinicians are used to prescribe empiric antibiotics rather than empiric antifungal agents; therefore, a significant proportion of candidemia (approximately 4 out of 10) did not receive effective therapy initially. Furthermore, the removal of CVC is also decided by the clinicians in our institute. Although removal of CVC is critically important when candidemia is documented [31], it usually requires the availability of an alternative intravascular route and that the patient is in stable condition.

This study has some limitations. Because of its retrospective nature in a single center, and also because follow-up blood cultures after having documented candidemia were not drawn regularly, it was sometimes difficult to differentiate persistent candidemia from early relapsed candidemia. The conclusion of this current study is also limited by the retrospective design and heterogenous enrolment of the subjects studied. Although MALDI-TOF can rapidly identify the Candida spp. in a sensitive and economical way, a major disadvantage is that the spectral database must contain peptide mass fingerprints of the new specific species; otherwise, misdiagnosis may happen [37]. Furthermore, undocumented candidemia in patients on empiric antifungal therapy may lead to unrepresented cases in this study and the underestimated incidence of candidemia. Therefore, a prospective study which mandates detailed and continuous diagnostic work in order to define the recurrence of an episode is warranted.

Supplementary Materials: The following are available online at http:/ /www.mdpi.com/2077-0383/8/1/99/s1, Table S1: Comparisons of early recurrent episodes and late recurrent episodes of candidemia in children.

Author Contributions: Conceptualization: M.Y.L. and M.H.T.; Methodology: M.Y.L., M.H.T. and J.F.H.; Formal Analysis: S.M.C., I.H.W., H.R.H. and M.Y.L.; Resources: J.F.H., S.M.C., I.H.W., H.R.H. and M.Y.L.; Investigation: M.C.C. and R.H.F.; Writing-Original Draft Preparation: M.Y.L.; Writing-Review and Editing: M.H.T. All authors 
made final approval of the current version of the manuscript as submitted to be published and agreement to be accountable for all aspects of this work in ensuring that questions related to the accuracy or integrity of any part of the work are appropriated investigated and resolved.

Funding: Chang Gung Medical Research Program Foundation (grants CMRPG3E1491). The statistical assistance was provided by the Clinical Trial Center, Chang Gung Memorial Hospital, Linkou, Taiwan, which was founded by the Ministry of Health and Welfare of Taiwan; MOHW106-TDU-B-212-113005.

Financial Disclosure: The authors have no financial relationships relevant to this article to disclose.

Acknowledgments: All authors thank Chiao-Ching Chiang for keeping the database of our NICU, and all nursing staff working in our NICUs for keeping extremely detailed patient records, which contributed greatly to the completion of this research. We thank financial support from the Chang Gung Medical Research Program Foundation (grants CMRPG3E1491). We thank Jang-Jih Lu (Department of Laboratory Medicine, Department of Medical Biotechnology and Laboratory Science Chang Gung Memorial Hospital at Linkou, Taoyuan, Taiwan) for providing the technical support of all Candida isolates re-identification and antifungal susceptibility testing. The authors wish to thank May Lu for her assistance in editing this manuscript and acknowledgement the support of the Maintenance Project of the Center for Big Data Analytics and Statistics (Grant CLRPG3D0044) at Chang Gung Memorial Hospital.

Conflicts of Interest: The authors declare no conflict of interest.

\section{References}

1. Reichert, F.; Piening, B.; Geffers, C.; Gastmeier, P.; Bührer, C.; Schwab, F. Pathogen-specific clustering of nosocomial blood stream infections in very preterm infants. Pediatrics 2016, 137, e20152860. [CrossRef]

2. Fernadez-Ruiz, M.; Guinea, J.; Lora-Pablos, D.; Zaragoza, O.; Puig-Asensio, M.; Almirante, B.; Cuenca-Estrella, M.; Aguado, J.M. Impact of fluconazole susceptibility on the outcome of patients with candidemia: Data from a population-based surveillance. Clin. Microbiol. Infect. 2017, 23, 672.

3. Montravers, P.; Perrigault, P.F.; Timsit, J.F.; Mira, J.P.; Lortholary, O.; Leroy, O.; Gangneux, J.P.; Guillemot, D.; Bensoussan, C.; Bailly, S.; et al. Antifungal therapy for patients with proven or suspected Candida peritonitis: Amarcand, a prospective cohort study in French intensive care units. Clin. Microbiol. Infect. 2017, 23, 117. [CrossRef] [PubMed]

4. Hesstvedt, L.; Gaustad, P.; Andersen, C.T.; Haarr, E.; Hannula, R.; Haukland, H.H.; Hermansen, N.O.; Larssen, K.W.; Mylvaganam, H.; Ranheim, T.E.; et al. Twenty-two years of candidaemia surveillance: Results from a Norwegian national study. Clin. Microbiol. Infect. 2015, 21, 938-945. [CrossRef]

5. Tsai, M.H.; Wang, S.H.; Hsu, J.F.; Lin, L.C.; Chu, S.M.; Huang, H.R.; Chiang, M.C.; Fu, R.H.; Lu, J.J.; Huang, Y.C. Clinical and molecular characteristics of bloodstream infections caused by Candida albicans in children from 2003 to 2011. Clin. Microbiol. Infect. 2015, 21, 1018. [CrossRef] [PubMed]

6. Blyth, C.C.; Chen, S.C.; Slavin, M.A.; Serena, C.; Nguyen, Q.; Marriott, D.; Ellis, D.; Meyer, W.; Sorrell, T.C. Not just little adults: Candidemia epidemiology, molecular characterization, and antifungal susceptibility in neonatal and pediatric patients. Pediatrics 2009, 123, 1360-1368. [CrossRef] [PubMed]

7. Tragiannidis, A.; Fegeler, W.; Rellensmann, G.; Debus, V.; Müller, V.; Hoernig-Franz, I.; Siam, K.; Pana, Z.D.; Jürgens, H.; Groll, A.H. Candidaemia in a European Paediatric University Hospital: A 10-year observational study. Clin. Microbiol. Infect. 2012, 18, E27-E30. [CrossRef] [PubMed]

8. Vogiatzi, L.; Ilia, S.; Sideri, G.; Vagelakoudi, E.; Vassilopoulou, M.; Sdougka, M.; Briassoulis, G.; Papadatos, I.; Kalabalikis, P.; Sianidou, L. Invasive candidiasis in pediatric intensive care in Greece: A nationwide study. Intensive Care Med. 2013, 39, 2188-2195. [CrossRef] [PubMed]

9. Santolaya, M.E.; Alvarado, T.; Queiroz-Telles, F.; Colombo, A.L.; Zurita, J.; Tiraboschi, I.N.; Cortes, J.A.; Thompson, L.; Guzman, M.; Sifuentes, J.; et al. Active surveillance of candidemia in children from Latin America: A key requirement for improving disease outcome. Pediatr. Infect. Dis. J. 2014, 33, e40-e44. [CrossRef] [PubMed]

10. Dutta, A.; Palazzi, D.L. Candida non-albicans versus Candida albicans fungemia in the non-neonatal pediatric population. Pediatr. Infect. Dis. J. 2011, 30, 664-668. [CrossRef] [PubMed]

11. Zaoutis, T.E.; Argon, J.; Chu, J.; Berlin, J.A.; Walsh, T.J.; Feudtner, C. The epidemiology and attributable outcomes of candidemia in adults and children hospitalized in the United States: A propensity analysis. Clin. Infect. Dis. 2005, 41, 1232-1239. [CrossRef] [PubMed] 
12. Steinbach, W.J.; Foilides, E.; Berman, D.; Hoffman, J.A.; Groll, A.H.; Bin-Hussain, I.; Palazzi, D.L.; Castagnola, E.; Halasa, N.; Velegraki, A.; et al. Results from a prospective, international, epidemiologic study of invasive candidiasis in children and neonates. Pediatr. Infect. Dis. J. 2012, 31, 1252-1257. [CrossRef]

13. Dotis, J.; Prasad, P.A.; Zaoutis, T.; Roilides, E. Epidemiology, risk factors and outcome of Candida parapsilosis bloodstream infection in children. Pediatr. Infect. Dis. J. 2012, 31, 557-560. [CrossRef] [PubMed]

14. Zaoutis, T.E.; Prasad, P.A.; Localio, A.R.; Coffin, S.E.; Bell, L.M.; Walsh, T.J.; Gross, R. Risk factors and predictors for candidemia in pediatric intensive care unit patients: Implications for prevention. Clin. Infect. Dis. 2010, 51, e38-e45. [CrossRef] [PubMed]

15. Lee, W.J.; Hsu, J.F.; Lai, M.Y.; Chiang, M.C.; Lin, H.C.; Huang, H.R.; Wu, I.H.; Chu, S.M.; Fu, R.H.; Tsai, M.H. Factors and outcomes associated with candidemia caused by non-albicans Candida spp versus Candida albicans in children. Am. J. Infect. Control. 2018, 46, 1387-1393. [CrossRef] [PubMed]

16. Muñoz, P.; Vena, A.; Valerio, M.; Álvarez-Uria, A.; Guinea, J.; Escribano, P.; Bouza, E. Risk factors for late recurrent candidemia. A retrospective matched case-control study. Clin. Microbiol. Infect. 2016, 22, 277. [CrossRef] [PubMed]

17. Asmundsdóttir, L.R.; Erlendsdóttir, H.; Gisladóttir, A.L.; Gottfredsson, M. Molecular epidemiology of late recurrent candidaemia-A population-based study in Iceland. Clin. Microbiol. Infect. 2012, 18, 195-201. [CrossRef]

18. Cuervo, G.; Garcia-Vidal, C.; Nucci, M.; Puchades, F.; Fernández-Ruiz, M.; Obed, M.; Manzur, A. Breakthrough candidaemia in the era of broad-spectrum antifungal therapies. Clin. Microbiol. Infect. 2015, 22, 181-188. [CrossRef]

19. Gamaletsou, M.N.; Daikos, G.L.; Walsh, T.J.; Perlin, D.S.; Ortigosa, C.J.; Psaroulaki, A.; Pagoni, M.; Argyropoulou, A.; Nepka, M.; Perivolioti, E.; et al. Breakthrough candidemia caused by phenotypically susceptible Candida spp. in patients with haematological malignancies does not correlate with established interpretive breakpoints. Int J. Antimicrob. Agents 2014, 44, 248-255. [CrossRef]

20. Bizerra, F.C.; Jimenez-Ortigosa, C.; Souza, A.C.; Breda, G.L.; Queiroz-Telles, F.; Perlin, D.S.; Colombo, A.L. Breakthrough candidemia due to multidrug-resistant Candida glabrata during prophylaxis with a low dose of micafungin. Antimicrob. Agents Chemother. 2014, 58, 2438-2440. [CrossRef]

21. Nguyen, M.H.; Wissel, M.C.; Shields, R.K.; Salomoni, M.A.; Hao, B.; Press, E.G.; Shields, R.M.; Cheng, S.; Mitsani, D.; Vadnerkar, A.; et al. Performance of Candida real-time polymerase chain reaction, $\beta$-D-Glucan Assay, and blood cultures in the diagnosis of invasive candidiasis. Clin. Infect. Dis. 2012, 54, 1240-1248. [CrossRef] [PubMed]

22. Jung, D.S.; Farmakiotis, D.; Jiang, Y.; Tarrand, J.J.; Kontoyiannis, D.P. Uncommon Candida species fungemia among cancer patients, Houston, Texas, USA. Emerg. Infect. Dis. 2015, 21, 1942-1950. [CrossRef] [PubMed]

23. Alexander, B.D.; Byrne, T.C.; Smith, K.L.; Hanson, K.E.; Anstrom, K.J.; Perfect, J.R.; Reller, L.B. Comparative evaluation of Etest and Sensititre YeastOne panels against the Clinical and Laboratory Standards Institute M27-A2 reference broth microdilution method for testing Candida susceptibility to seven antifungal agents. J. Clin. Microbiol. 2007, 45, 698-706. [CrossRef] [PubMed]

24. Orasch, C.; Marchetti, O.; Garbino, J.; Schrenzel, J.; Zimmerli, S.; Mühlethaler, K.; Pfyffer, G.; Ruef, C.; Fehr, J.; Zbinden, R.; et al. Candida species distribution and antifungal susceptibility testing according to European Committee on Antimicrobial Susceptibility Testing and new vs. old Clinical and Laboratory Standards Institute clinical breakpoints: A 6-year prospective candidaemia survey from the fungal infection network of Switzerland. Clin. Microbiol. Infect. 2014, 20, 698-705. [PubMed]

25. Clinical and Laboratory Standards Institute. Reference Method for Broth Dilution Antifungal Susceptibility Testing of Yeasts: 4th Informational Supplement; Document M27-S4; Clinical and Laboratory Standards Institute: Wayne, PA, USA, 2012.

26. Pfaller, M.A.; Diekema, D.J. Progress in antifungal susceptibility testing of Candida spp. by use of Clinical and Laboratory Standards Institute broth microdilution methods, 2010 to 2012. J. Clin. Microbiol. 2012, 50, 2846-2856. [CrossRef]

27. Kumamoto, C.A. Inflammation and gastrointestinal Candida colonization. Curr. Opin. Microbiol. 2011, 14, 386-391. [CrossRef]

28. Clancy, C.J.; Barchiesi, F.; Falconi DiFrancesco, L.; Morris, A.J.; Snydman, D.R.; Yu, V.L.; Scalise, G.; Nguyen, M.H. Clinical manifestations and molecular epidemiology of late recurrent candidemia, and implications for management. Eur. J. Clin. Microbiol. Infect. Dis. 2000, 19, 585-592. [CrossRef] [PubMed] 
29. Da Matta, D.A.; Melo, A.S.; Guimaraes, T.; Frade, J.P.; Lott TJColombo, A.L. Multilocus sequence typing of sequential Candida albicans isolates from patients with persistent or recurrent fungemia. Med. Mycol. 2010, 48, 757-762. [CrossRef]

30. Shih, J.H.; Shin, D.H.; Song, J.W.; Kee, S.J.; Suh, S.P.; Ryang, D.W. Electrophoretic karyotype analysis of sequential Candida parapsilosis isolates from patients with persistent or recurrent fungemia. J. Clin. Microbiol. 2001, 39, 1258-1263.

31. Tsai, M.H.; Hsu, J.F.; Chu, S.M.; Chang, P.J.; Lai, M.Y.; Wu, I.H.; Huang, H.R.; Chiang, M.C.; Fu, R.H.; Lu, J.J. Clinical and microbiological characteristics, and impact of therapeutic strategies on the outcomes of children with candidemia. Sci. Rep. 2017, 7, 1083. [CrossRef]

32. Tsai, M.H.; Chu, S.M.; Lee, C.W.; Hsu, J.F.; Huang, H.R.; Chiang, M.C.; Fu, R.H.; Lien, R.; Huang, Y.C. Recurrent late-onset sepsis in the neonatal intensive care unit: Incidence, clinical characteristics and risk factors. Clin. Microbiol. Infect. 2014, 20, O928-O935. [CrossRef]

33. Lagunes, L.; Borgatta, B.; Martin-Gomez, M.T.; Rey-Pérez, A.; Antonelli, M.; Righi, E.; Merelli, M.; Brugnaro, P.; Dimopoulos, G.; Garnacho-Montero, J.; et al. Predictors of choice of initial antifungal treatment in intra-abdominal candidiasis. Clin. Microbiol. Infect. 2016, 22, 719-724. [CrossRef] [PubMed]

34. Auchtung, T.A.; Fofanova, T.Y.; Stewart, C.J.; Nash, A.K.; Wong, M.C.; Gesell, J.R.; Auchtung, J.M.; Ajami, N.J.; Petrosino, J.F. Investigating colonization of the healthy adult gastrointestinal tract by fungi. mSphere 2018, 3 , e00092-18. [CrossRef]

35. Soldini, S.; Posteraro, B.; Vella, A.; De Carolis, E.; Borghi, E.; Falleni, M.; Losito, A.R.; Maiuro, G.; Trecarichi, E.M.; Sanguinetti, M.; et al. Microbiological and clinical characteristics of biofilm-forming Candida parapsilosis isolates associated with fungaemia and their impact on mortality. Clin. Microbiol. Infect. 2018, 24, 771-777. [CrossRef] [PubMed]

36. Muñoz, P.; Agnelli, C.; Guinea, J.; Vena, A.; Álvarez-Uria, A.; Marcos-Zambrano, L.J.; Escribano, P.; Valerio, M.; Bouza, E. Is biofilm production a prognostic marker in adults with candidemia? Clin. Microbiol. Infect. 2018, 24, 1010-1015. [CrossRef]

37. Singhal, N.; Kumar, M.; Kanaujia, P.K.; Virdi, J.S. MALDI-TOF mass spectrometry: An emerging technology for microbial identification and diagnosis. Front. Microbiol. 2015, 6, 791. [CrossRef] [PubMed] 